\title{
A Review on Tips \& Tricks for Stress Management in Working People
}

\author{
Ashutosh Tripathi, Shivani Nagpal and Poorva Gupta \\ Department of Psychiatry, Shree Guru Gobind Singh Tricentary \\ University, Gurugram, Haryana, India \\ Corresponding author email: shivaninagpal17589@gmail.com
}

\section{ABSTRACT}

In Indian history, women were more likely to handle only house hold works but as time changes now, women handle not only, office work but house hold works as well so situations become stressful for them. In this paper, some stress management techniques have been discussed in order to improve health conditions and to spread awareness regarding how stress ruin not only health but overall lifestyle and thinking. The effects of stress on brain and children along with working persons has been shared with the help of this paper. Stress management could not be handled within few hours or days, it is little long process to reflect its results. Thus, for better future \& healthy life, it is required to take some important steps now so that we can have better stress management strategies in future.

KEY WORDS: MANAGEMENT OF STRESS, STRESS, TECHNIQUES TO MINIMIZE STRESS.

\section{INTRODUCTION}

Stress is a mental state in which psychological disturbances experienced by a person. Stress may be defined as a fact of life, at every stage of life, we found someone in stress and stress should not be ignored because it gives a negative impact on life. Life is second name of changes and one should keep in mind that changes that causes stress can be attempted as positive changes as well. Therefore, stress can be termed as the way in which humans react to a situation mentally and physically. Some of the cognitive symptoms of stress are: memory problem, poor judgement, constantly worrying about something, lack of focus, moodiness, anger and irritation and many more(T. Ehrenfeld et. at.). Stress is one of the major problem faced by millions of the people at work stations and in personal life as well. American psychological association (APA) has described various types of stress as illustrated in Figure1.

Biosc Biotech Res Comm P-ISSN: 0974-6455 E-ISSN: 2321-4007

\section{crossef}

Identifiers and Pagination

Year: 2021 Vol: 14 No (6) Special Issue

Pages: $380-384$
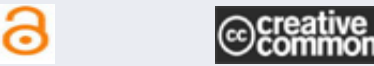

Article Information

Received: $11^{\text {th }}$ May 2021

This is an open access article under Creative

Commons License Attribn 4.0 Intl (CC-BY).

DOI: $h$ ttp://dx.doi.org/10.21786/bbrc/14.7.80
1. Type of Stress: Mainly three types of stress are described given below:

American association of psychology had stated that by knowing which type of stress is faced, it become easy to reduce it so, stress has been categorized in three parts (Figure 1).

Figure 1: Types of Stress according to American Psychological Association

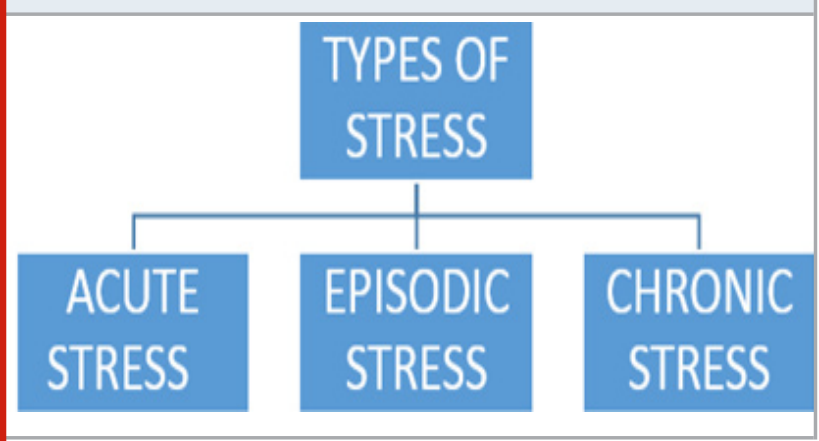

1.1. Acute stress: It may be defined as a situation based stress for example: when someone has deadlines regarding official work and sudden need to go somewhere in children school and instantly need to drive then all in hurry and instantly barely missed an accident. In this situation, the

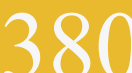


mental stress, experienced by one is called as acute stress. Anxiety, mentally disturbance, headache etc. are some symptoms of acute stress.

1.2. Episodic stress: It is one of the types of stress in which a person experiences these small crises on daily basis in life and stay tense every day. A general form of tension is always remains in mind of episodic stressed person. The symptoms are common to acute stress. To deal with episodic stress, physical exercise is recommended that helps to boost up positivity in body and mind.

1.3. Chronic stress: It is one the most common form of stress experienced by many of us which is generally ignored and left uncured. It generated from serious life issues like racism, childhood torture, poverty, bullying in school, these are the reasons that cause chronic stress. These stress are generated under those factor that are not in our control. The disadvantage of chronic stress is that one cannot predict when this chronic stress is going to be end. Children with a traumatic childhood experience are the victims of chronic stress. Related causes of chronic stress lies in mind always and being a victim of this, most of the time people stop fighting against stress and start living comfortably within stressful life(T. Ehrenfeld et. at.).

2. Causes of Stress: As already mention that, stress may be caused by many reasons. Some of the reasons are listed below as.

2.1. Work pressure at office: It is a natural human tendency that under some mental pressure human do not behave appropriate and females are more likely to have mental pressure soon as compared to males which creates a tension in brain and this tension hamper the thinking ability to perform task in office.

2.2. Mismanagement in daily life tasks: As women have to handle all work from home and office and family management too in general therefore it become difficult to manage all the time all the task for them which leads to mismanagement and stress formation due to hectic schedule.

2.3. Unsupported family members: In India, females have to manage after wedding between in laws therefore, many of the cases has been reported of dowry harassment and many other reasons which hamper the mental health. So it is very important to have a supported family member to cooperate with females.

2.4. Prefacing health issues: If females are facing some health issues already, that can also cause, stress. Due to some medical problems like high BP, Diabetic patient, hormonal issues, these factors can cause stress to females in general life.

2.5. Side effects of medicines: Allopathy medicines do have some side effects which affects the health when used in long terms. For example: metformin and Glycomet are the medicines that exerts some of side effects like excessive hair fall and acne on face. Like these, other medicines also have some side effects that reflects in patient's health. These side effects can cause stress too.

2.6. Overthinking: Overthinking is a psychological disease which has no specific cause but it has many dangerous effects and results. Overthinking can shrink the thinking area for someone as one keeps thinking about only one specific problem. Due to overthinking, strain is generated in brain muscles that cause headache and hormonal misbalance.

2.7. Lack of good eating habits: Due to lack of good eating habits, not only mental health but physical health is also affected a lot because of deficient amount of fibrous diet and essential vitamins that are very much essential for female health.

2.8. Accidental History: Accident can be experienced by anyone, any kind of major accident in past can be reason of stress, if one is not capable to come out of it mentally. Either some one's death or any major injury has a direct impact on someone's mental health \& stress.

2.9. Emotional Health: Stress is directly related to emotional health. In our general daily life, it is observed that people who remain happy are less likely to have stress even if they do have stress that tackle it with easily, it is observed that people who remain happy are less likely to have stress even if they do have stress that tackle it with easily. On other hand, those people who usually remain sad are always found to be stress full and lives tension full life. It means emotional health is very important for all of us specifically females.

2.10. Lack of physical activities: Regular exercise and physical activities are two main factors, if lacking these factors, not only stress but many other health issues can be faced by females and males as well. body become lethargic and less active by lack of exercise(L. Varvogli et. al. (2011).

3. Symptoms of Stress: As stress is a mental and psychological state of human mind therefore, it is obvious to say that every stressed female reacts in different ways to stress. Some of the common symptoms of stress usually found as per recent studies are headache, fatigue, anxiety, sleep disorder, hypertension, heart related problem, gastrointestinal problems, disturbance in focus, shaking hands and sweat in palm and many more. These common features of stress are globally identified. It is found that majority of the population used to ignore these symptoms, and do not consider stress as a serious problem. However, stress is a term that requires to pay attention to treat it as well as, to diagnose the causes because stress is something that not only affect physical body but mental health and psychological thinking as well. A physiatrist can help in terms of sharp observation and expert guidance to help a stresses patient. Medicines do cure stress but, somewhere, stress is defined as a feeling and it can be cured by improving self-observation and taking care of one self. Causes of stress 
can be different however, symptoms of stress are generally found to be same everywhere. Proper medications can help to treat specific stress types.(R. Burman et. al. (2018).

4. Stress Management Techniques: Stress is a global psychological problem that is ignored by many of people due to fear of not being able to be adopted by society, therefore people ignore its existence and do not try to deal with it. Some of the stress management techniques has been discussed here below in Figure 2. Various type of stress management techniques is illustrated which has different impact on different people depending upon, which kind of stress a person does exerts. These techniques are generally used on stressed people in order to reduce anxiety (G K. Kristofersson et. al (2013).

Figure 2: Different Types of Stress Management Techniques

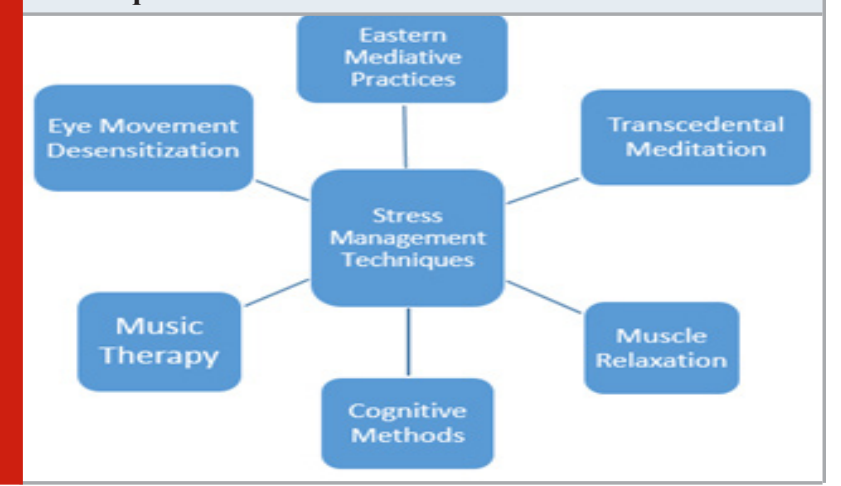

Multiple types of stress are caused by different types of causes. Few of the causes of stress are unsettling effect of changes in life. If one is experiencing disturbance in life pattern any problem of not being settled in life that may suffer from stress. Another case is if any outside force is challenging or threatening that also may cause stress. External force could be any person or thief or may be any blackmailer that creates situations like fear or stress, excessive sweating, high heart beats and many more restless situations which ultimately causes stress. On the other hand, one can be stressed by assuming mentally that, self-control is not in well-handled condition. In this scenario, stress patient is more responsible for generating stressful thoughts and not able to manage things in life. So these three factors are general causes of stress. Very often stress patient can help its own to fight against stress by feeling good and strong determination to improve. Causes of stress can be easily identified by self-observation also.

5. Stress as initiator of depression: There are many ways in which stress can act like a seed to grow depression plants in mind. Here are some of the reasons like early life stress that can generate the enhanced emotional \& neuroendocrine activity that further, creates a phenotype of depression. Glucocorticoid receptor (GR) antagonist increases psychotic symptoms whereas the mineralocorticoid receptor (MR) antagonist worsens the antidepressant outcomes. Thus, stress can effect adversely humans hormones and even alter them in a way which cause depression(E. R. De Kloet. et. al (2005).
Review Of Literature: M. Mehta et al. discussed their views on stress management and main focus is on how stress affects the life of adolescents. According to author, stress is a serious problem and everybody reacts to stress in different ways. Stress can be identified in a person in the form of physical or psychological, social forms. Author states that it's a human tendency to ignore the existence of stress in life. Different stress management techniques have been discussed. Stress assessing strategies using interview and self-report has been provided by author(M. Mehta et. al (2015). C. Stefanaki et al. has purposed a report on stress in PCOS women, considering that PCOD/PCOS is also one of the major reason of stress in females which is an endocrine disorder. In this paper author has presented a report on trial randomly conducted just to explore the effect of mindfulness stress management program in which a measure is setup on depression, stress and anxiety. In this program early morning sample for LH, FSH has been collected with overnight fasting and study of this program got approval from research ethics committee as well(C. Stefanaki et. al (2015).

Martin. Prince et al. has described about the effect of global burden of diseases that contributes to neurological disorders which is basically caused due to chronical imbalance. Author has discussed about, stress and mental disorder, how they affect overall mental health and also bring light on importance of mental health. Burden of mental disorder is usually underestimated due to mental illness and not able to adopt socially.

Therefore, it is not wrong to say that there can be no health without mental health(M. Prince et. al (2007). Patrycja Miedziun et al. had presented a review on techniques to coping stress that are generally used by most of the population. Also, author has focused on what are those techniques by which stress can be managed that are adopted by those people who have more stress in life. A questionnaire method on stress related techniques has been used by author in this paper. Author have attempted questionnaire on sample of 100 people selected randomly whose age is around 34 years. Problem solving and vicarious gratification these two categories of stress management techniques have been used by most of the people according to author in stress management survey(M. Patrycja et. al (2015).

S. Michie et al. had discussed about techniques for managing stress and mentioned some of the steps related to what changes one should bring in life $\&$ in one self to deal with stress. According to author, changes can be observed in two ways first one is change in one's situation second one is change in self. Situation based changes can be social, physical and at work, however change in self can be brought in two directions such as active coping and rest $\&$ rehabitutaion. Except these factor, author has mentioned some steps to reduce stress like exercise, distraction \& acceptance, relaxation, holiday break, managing time, priorities, eating drinking habits, sleeping pattern, selfmonitoring and many more points has been discussed in article(S. Michie et. al (2002). 
In above research studies, different lifestyle changes had been discussed that helps to deal with stress. Survey has been done on about 100 of population to get information about their stress levels and some of the author focused on global effect of diseases in neurological stress terms. Where the practical and natural remedies have been missing in these studies. In purposed methodology, the focus is on type of physical activities and small effective changes in lifestyle, healthy eating habits has been suggested. Desired results collected from considered samples are shared further.

\section{METHODOLOGY}

A small survey has been done for practicing purposed methodology nearby park behind Rama-Krishna temple, and some general questions were asked to randomly selected people and 4 cases has been selected that are found stressed. These selected people agreed to follow our methodology for a month and their response was recorded. To deal with stress in case of working people including, men women, youngsters, adults all groups have been considered as stress can disturb anyone and respectively their life has an impact of this. So, purposed methodology is designed accordingly, in which some activities have been suggested to practice in order to reduce and deal with stress. However, there is no such fixed pattern to deal with stress or to reduce stress, even then a methodology has been designed to tackle with stress. The purposed methodology has been divided into two main categories as illustrated in Figure $4 \& 5$ physical and psychological remedies. In physical remedies below are the methods that can be adopted in daily routine.

Figure 4: Physical Methods to be adopted in daily routine to reduce stress.

\section{PHYSICAL REMEDIES}

STRECHING AND EXERCISE IN PARK

YOGA AND DHYAN/ASANA

BREATHING PRACTICES LIKE ANULOM-VILOM \& PRANAYAM

CHANGE LOCATION/ HOLIDAYS

READING MAGAZINES, BOOKS

MUSIC THERAPY \& DANCE

WATCHING GOOD MOVIE OR SERIES

COMMUICATION WITH DEAR ONES

DRINK LOT OF WATER SO THAT BODY RELEASE TOXIC

10. EATING HEALTHY FOOD

11. FOCUS ON PHYSICAL HEALTH

12. MORNING EVENING WALK
13. INDULGE IN NATURAL THINGS LIKE FRESH AIR, SUN

14. TAKING CARE OF SELF

Figure 5: Psychological Remedies

\section{PSYCOLOGICAL REMEDIES}

JOIN A COMMUNITY THA T HELPS STRESSED PEOPLE

CONSULT A PSYCHAITRY DOCTOR
TRY TO BE IN PEACE ALONE TO CALM MIND

MEETING NEW PEOPLE AY HAVE GOOD IMPACT ON MIND READING BLOGS AND ADOFTING CHANGES IN LIFE WITH ACCEPTANCE

AVOID OVERTHINKING

AVOID OVERTHINKING
AVOID NEGATIVE THOUGHT

AVOID NEGA TIVE THOUGHT
FEELING POSITIVE VIBES

9. SURR OUND WITH THINGS THAT GIVES HAPPINESS

10. DONOT FEEL DEMOTIVA TED OR LOST IN LIFE MENTALLY

By adopting these practices in daily routine one can definitely deal with stress and even reduce stress up to an extent because when healthy eating habits has been adopted by someone, body starts responding accordingly. Physical activities if performed in a regular manner in daily life, can boost up immunity level up to an extent. High immunity help to fight against diseases and provides strength to provide resistance to diseases that are easily catchable like common cold fever etc. Muscles building and muscle recovery in case of injury will be a faster in comparison of one who do not exercise regularly. Some of the activities are so easy to adopt such as drinking lot of water enhance the overall metabolism of body and keeps body hydrated with passage of toxic substances out of body and by doing exercise daily, body remains fit which boost up the good hormones in body thus overall these points will help to reduce stress in working people.

By following these psychological practices in daily routine accordingly, one can cure stress for sure but the man principle is that stress cannot be reduced within one or two day or in a month, to deal with stress perfectly, one should be determined to follow these steps both physically and psychologically for best results.

Table 1. Results from Case Study

\begin{tabular}{|l|c|c|c|l|}
\hline $\begin{array}{l}\text { Parameters } \\
\text { from (A to D) }\end{array}$ & A & B & C & D \\
\hline Case 1 & Work pressure & 25 & Good & 7 \\
\hline Case 2 & Family issues & 17 & Average & 6 \\
\hline Case 3 & Health issues & 27 & Excellent & 8 \\
\hline Case 4 & Financial issue & 23 & Ok & 5 \\
\hline
\end{tabular}

\section{RESULTS AND DISCUSSION}

Out of four cases, three of them are satisfied with purposed methodology, they have shared their experience in terms of
A. Reason of stress B. Number of days the purposed methodology is
followed
C. Real time feeling after one month
D. Ten point score based on recovery from stress

Below are the experiences shared by four sample persons (Table 1) along with defined parameters to measure the effect of purposed methodology.

In above discussion, case 3 has been suggested to follow purposed methodology specifically physical section in order to overcome health issues for better results and case 4 has been suggested to tackle the problems with a better understanding and maintenance between income and expenditure to reduce stress about financial problems. However, case 2 was stressed due to family issues which is a dependent factor on family members and can be vary person to person and according to the situations in family. Case 1 is really satisfied by following the suggested methods and found a better experience to deal with stress ant work. 


\section{CONCLUSION}

The main problematic issue is to deal with stress effectively and naturally because medicines have side effects, treatment on the basis of complete medicines would not be a good solution. Stress should be dealt in a way that benefits the mental health as well as physical health. Many researchers had suggested different ways to minimize stress in their own ways. In present research work, effective and natural methods have been suggested for the treatment of stress that are easy to adopt and cost effective solutions. The purposed methods do not pursue any kind of side effects. From future perspective these methodologies can be shared with multiple number of people who experience stress, and awareness programs can be held for sharing the findings. Small free camps can be organized to spread awareness among societies and people so that working people can deal with stress in a better way. Seminars can be organized in schools and colleges on how to deal with stress and how stress ruin mental health of people. Live sessions can be conducted on importance of mental health. So that more and more people become aware about stress management, healthier citizens will be there in our societies.

\section{REFERENCES}

Burman, R. and Goswami, T.G., 2018. A systematic literature review of work stress. International Journal of Management Studies, 5(3-9), pp.112-132.

De Kloet, E.R., 2005. Joels M, Holsboer F. Nat Rev
Neurosci, 6, pp.463-475.

Kristofersson, G.K. and Kaas, M.J., 2013. Stress management techniques in the prison setting. Journal of forensic nursing, 9(2), pp.111-119.

Mehta, M. and Sagar, R. eds., 2015. A practical approach to cognitive behaviour therapy for adolescents. Springer.

Michie, S., 2002. Causes and management of stress at work. Occupational and environmental medicine, 59(1), pp.67-72.

Miedziun, P. and Czabała, J.C., 2015. Stress management techniques. Arch Psychiatry Psychother, 17(4), pp.2331 .

Prince, C.D. and Scheurman, P.J., others.(2009). The Other 69 Percent: Fairly Rewarding the Performance of Teachers of Non-Tsted Subjects and Grades. Center for Educaor Compensation Reform.

Stefanaki, C., Bacopoulou, F., Livadas, S., Kandaraki, A., Karachalios, A., Chrousos, G.P. and Diamanti-Kandarakis, E., 2015. Impact of a mindfulness stress management program on stress, anxiety, depression and quality of life in women with polycystic ovary syndrome: a randomized controlled trial. Stress, 18(1), pp.57-66.

Varvogli, L. and Darviri, C., 2011. Stress management techniques: Evidence-based procedures that reduce stress and promote health. Health science journal, 5(2), p.74. 